\title{
Do checkpoint inhibitors provide new hope for management of metastatic penile carcinoma?
}

\author{
Roland Eid*,1, Elie Nemr ${ }^{2}$, Fady GH Haddad ${ }^{1}$, Hampig Raphael Kourie ${ }^{1}$ \& Joseph Kattan ${ }^{1}$ \\ ${ }^{1}$ Faculty of Medicine, Hematology-Oncology Department, Saint-Joseph University, Beirut, Lebanon \\ ${ }^{2}$ Faculty of Medicine, Urology Department, Saint-Joseph University, Beirut, Lebanon \\ * Author for correspondence: Tel.: +961 300 4741; roland.eid@net.usj.edu.lb

\section{"Checkpoint inhibitors represent nowadays a new hope for orphan malignancies, such as metastatic penile carcinoma."}

First draft submitted: 20 October 2017; Accepted for publication: 20 November 2017; Published online: 9 March 2018

Keywords: checkpoint inhibitors $\bullet$ metastatic $\bullet$ ongoing trials $\bullet$ PD-L1 $\bullet$ penile carcinoma $\bullet$ preliminary results $\bullet$ rare cancers $\bullet$ rationale $\bullet$ standard therapy $\bullet$ treatment

Penile carcinomas are rare in the USA, Europe and other industrialized countries [1]. In contrast, their incidence is significantly higher in some less developed countries in South America, Africa and Asia, accounting for as much as $10-20 \%$ of male cancers $[2,3]$. The annual incidence of penile squamous cell carcinoma (SCC) increases with age, with a median age of 68 years $[4,5]$.

Many factors are known to increase the risk of developing a precursor lesion or a SCC of the penis, such as phimosis, HPV, HIV and tobacco exposure [6-9]. A number of medical conditions are also associated with an increased risk of developing penile cancer: a history of penile injury, tear, or chronic rash lasting one month or longer; a history of urethral structure, urinary tract infection or genital warts [8]. It is interesting to note that sexual orientation (heterosexual, bisexual/homosexual) is not a risk factor for penile cancer [9].

The majority of penile cancers are diagnosed at a local stage (61\%); these cancers are characterized by early locoregional spread with subsequent potential for distant dissemination [10]. Disseminated metastatic penile cancers are treated based on the localizations of the metastases, the symptoms of the patients and their performance status [11]. In general, for the treatment of metastatic penile cancer, systemic chemotherapy, radiation therapy or chemoradiation can be considered [12]. Given the rarity of penile cancer, there are no randomized clinical trials to define the preferred chemotherapeutical regimen [13,14].

With the tsunami of checkpoint inhibitors during the last 3 years, these potent anticancer agents showed remarkable results in the management of different malignancies. During the last few years, checkpoint inhibitors were approved in melanoma, non-small-cell lung cancer, bladder cancer, squamous cell head and neck cancer, renal cell carcinoma and Hodgkin's lymphoma. They were tested in rare cancers where no strong standard of care treatment was present [15].

We aimed in this paper to first describe the standard treatment of metastatic penile cancer. Given the fact that checkpoint inhibitors are demonstrating promising results in different malignancies, we then focused on their potential role in the management of this rare disease based on histology, risk factors and ongoing trials results.

\section{The rationale behind the use of checkpoint inhibitors in metastatic penile cancers}

In the absence of highly efficient therapies in the treatment of metastatic penile carcinoma, this rare tumor seems to be an interesting landscape for exploring checkpoint inhibitors. Different histologic, epidemiologic and therapeutic aspects encouraged researchers to test this drug in this malignancy. In fact, checkpoint inhibitors showed interesting results in virus-induced cancer, namely those related to HPV in SCC of the head and neck, the cervix and the anus [16]. This is mainly attributed to a specific immunologic profile probably related to a higher mutational load of these tumors and a higher expression of PD-L1 [17]. Moreover, these tumors had a similar histologic (squamous

Future $\because$ Medicine 
cell tumors), epidemiologic (viral-induced tumors) and therapeutic (platinum and anti-EGFR agents sensitive) background, probably leading to the same possible benefits from these agents in this indication. In parallel, different trials confirmed the presence of a high expression of PD-L1 in advanced penile SCC, therefore supporting the rationale of targeting immune-checkpoint inhibitor pathways [18].

\section{Standard treatment of metastatic penile cancer}

Paclitaxel plus ifosfamide plus cisplatin is a reasonable first-line treatment for patients with metastatic penile cancer, including palliative treatment of patients with distant metastases. 5-FU plus cisplatin can also be considered as an alternative to paclitaxel plus ifosfamide plus cisplatin $[19,20]$. Bleomycin-containing regimens are no longer recommended because of pulmonary-related toxicity [21]. Until now, no standard subsequent-line systemic therapy exists. Moreover, there is no strong evidence to support the palliative use of a second-line therapy [22].

Curative treatment of metastatic penile cancer is limited to lymphatic metastases. In such cases of limited lymph node metastases, surgery followed by adjuvant chemotherapy can be curative [23,24]. Also, in fit patients with an objective response to systemic chemotherapy, surgical consolidation (e.g., inguinal lymph node dissection) with curative potential or palliation should be considered [12]. Moreover, postoperative radiotherapy can be offered depending on the amount of residual disease after chemotherapy [25]. In the same perspective of improving surgical results, and therefore decreasing local recurrence, preoperative radiotherapy should be considered in the presence of lymph nodes greater than or equal to $4 \mathrm{~cm}$ without skin fixation [26].

Local symptomatic control can be managed with surgery or radiotherapy [27].

Patients with distant metastases and poor performance status or cases refractory to the previously mentioned palliative treatments should be managed with best supportive care [28,29].

\section{Preliminary results in metastatic penile cancers}

In ESMO 2017, some promising preliminary results on metastatic penile cancer cohort in the Phase II trial (NCT02496208) comparing cabozantinib/nivolumab/ipilimumab to cabozantinib/nivolumab showed a partial response in $50 \%$ of the patients $(2 / 4)$ and a stable disease in the other $50 \%(2 / 4)$. No other data concerning the results of checkpoint inhibitors in metastatic squamous penile carcinoma are reported in the literature.

\section{Ongoing trials using checkpoint inhibitors in metastatic penile cancers}

However, many ongoing trials are evaluating checkpoint inhibitors, namely nivolumab and pembrolizumab, in advanced penile SCC. A Phase II trial of 35 patients is testing pembrolizumab as single agent following chemotherapy with objective response rate as a primary outcome (NCT02837042). Another Phase II trial of 250 patients is evaluating the same agent in different rare cancers, including penile SCC, after failure of a prior treatment; nonprogression rate is the primary outcome (NCT02721732). Two Phase I trials are testing HPV specific $T$ cells after lymphodepletion in combination with nivolumab or pembrolizumab in advanced HPV-related carcinoma; the primary outcomes are dose limiting toxicity and safety (NCT02379520, NCT02858310). Finally, a Phase II trial of 334 patients is evaluating the combination of nivolumab and ipilimumab in advanced rare cancers, including advanced squamous penile carcinoma (NCT02834013).

\section{Conclusion \& future perspective}

Checkpoint inhibitors represent nowadays a new hope for orphan malignancies, such as metastatic penile carcinoma. In fact, the histologic, epidemiologic and therapeutic characteristics of these tumors support the rationale of administering checkpoint inhibitors in these patients. Some encouraging preliminary results are recently reported, rendering these agents very promising in this indication. New study designs should try to combine these new agents with traditional standard of care in order to show benefit in earlier lines of treatment. Nevertheless, determining specific predictive biomarkers in metastatic penile cancers remains an important challenge, with the main objective being the ability to administer the right drug to the right patient.

Financial \& competing interests disclosure

The authors have no relevant affiliations or financial involvement with any organization or entity with a financial interest in or financial conflict with the subject matter or materials discussed in the manuscript. This includes employment, consultancies, honoraria, stock ownership or options, expert testimony, grants or patents received or pending, or royalties.

No writing assistance was utilized in the production of this manuscript. 


\section{References}

Papers of special note have been highlighted as: $\bullet$ of interest; $\bullet \bullet$ of considerable interest

1. Siegel RL, Miller KD, Jemal A. Cancer statistics. CA Cancer J. Clin. 67(1), 7-30 (2017).

2. Solsona E, Algaba F, Horenblas S, Pizzocaro G, Windahl T. European Association of Urology. EAU guidelines on penile cancer. Eur. Urol. 46(1), 1-8 (2004).

3. Ornellas AA. Management of penile cancer. J. Surg. Oncol. 197(3), 199-200 (2008).

4. Hernandez BY, Barnholtz-Sloan J, German RR et al. Burden of invasive squamous cell carcinoma of the penis in the United States, 1998-2003. Cancer 113(10 Suppl.), 2883-2891 (2008).

5. Favorito LA, Nardi AC, Ronalsa M, Zequi SC, Sampaio FJB, Glina S. Epidemiologic study on penile cancer in Brazil. Int. Braz. J. Urol. 34(5), 587-593 (2008).

6. Miralles-Guri C, Bruni L, Cubilla AL, Castellsagué X, Bosch FX, de Sanjosé S. Human papillomavirus prevalence and type distribution in penile carcinoma. J. Clin. Pathol. 62(10), 870-878 (2009).

7. Harish K, Ravi R. The role of tobacco in penile carcinoma. Br. J. Urol. 75(3), 375-377 (1995).

8. Dillner J, von Krogh G, Horenblas S, Meijer CJ. Etiology of squamous cell carcinoma of the penis. Scand. J. Urol. Nephrol. Suppl. 205, 189-193 (2000).

9. Daling JR, Madeleine MM, Johnson LG et al. Penile cancer: importance of circumcision, human papillomavirus and smoking in in situ and invasive disease. Int. J. Cancer 116(4), 606-616 (2005).

10. Barnholtz-Sloan JS, Maldonado JL, Pow-sang J et al. Incidence trends in primary malignant penile cancer. Urol. Oncol. 25, 361-367 (2007).

11. Connell CF, Berger NA. Management of advanced squamous cell carcinoma of the penis. Urol. Clin. North Am. 21(4), 745-756 (1994).

12. Pettaway CA, Pagliaro L, Theodore C, Haas G. Treatment of visceral, unresectable, or bulky/unresectable regional metastases of penile cancer. Urology 76(2 Suppl. 1), S58-S65 (2010).

13. Barski D, Georgas E, Gerullis H, Ecke T. Metastatic penile carcinoma - an update on the current diagnosis and treatment options. Cent. European J. Urol. 67(2), 126-132 (2014).

14. Kattan J, Culine S, Droz JP et al.Penile cancer chemotherapy: twelve years' experience at Institut Gustave-Roussy. Urology 42(5), 559-562 (1993).

15. Kourie HR, Awada G, Awada A. The second wave of immune checkpoint inhibitor tsunami: advance, challenges and perspectives. Immunotherapy 9(8), 647-657 (2017).

- Important because it highlighted the updates on debatable issues related to checkpoint inhibitors.

16. Kanaan H, Kourie HR, Awada AH. Are virus-induced cancers more sensitive to checkpoint inhibitors? Future Oncol. 12(23), 2665-2668 (2016).

17. Udager AM, Liu T-Y, Skala SL et al. Frequent PD-L1 expression in primary and metastatic penile squamous cell carcinoma: potential opportunities for immunotherapeutic approaches. Ann. Oncol. 27(9), 1706-1712 (2016).

-. Evaluates the expression of PD-L1 in metastatic penile carcinoma.

18. Cocks M, Taheri D, Ball MW et al. Immune-checkpoint status in penile squamous cell carcinoma: a North American cohort. Hum. Pathol. 59, 55-61 (2017).

-. This is the largest study to assess the expression of PD-L1 in a cohort of penile squamous cell carcinoma.

19. Pagliaro LC, Williams DL, Daliani D et al. Neoadjuvant paclitaxel, ifosfamide, and cisplatin chemotherapy for metastatic penile cancer: a Phase II study. J. Clin. Oncol. 28(24), 3851-3857 (2010).

20. Di Lorenzo G, Buonerba C, Federico P et al. Cisplatin and 5-fluorouracil in inoperable, stage IV squamous cell carcinoma of the penis. BJU Int. 110(11 Pt B), e661-e666 (2012).

21. Haas GP, Blumenstein BA, Gagliano RG et al. Cisplatin, methotrexate and bleomycin for the treatment of carcinoma of the penis: a Southwest Oncology Group study. J. Urol. 161(6), 1823-1825 (1999).

22. Wang J, Pettaway CA, Pagliaro LC. Treatment for metastatic penile cancer after first-line chemotherapy failure: analysis of response and survival outcomes. Urology 85(5), 1104-1110 (2015).

23. Hakenberg OW, Protzel C. [Surgical treatment of metastatic penile cancer - what is the scientific rationale?] Urologe A 56(5), 624-626 (2017).

- Discusses the curable benefit of surgery in limited lymph node metastasis in penile cancer.

24. Hakenberg OW, Compérat EM, Minhas S et al. EAU guidelines on penile cancer: 2014 update. Eur. Urol. 67(1), 142-150 (2015).

- Provides an evidence-based update of treatment recommendations for penile cancer.

25. Pagliaro LC, Crook J. Multimodality therapy in penile cancer: when and which treatments? World J. Urol. 27(2), 221-225 (2009).

26. Richter S, Ruether JD, Wood L et al. Management of carcinoma of the penis: consensus statement from the Canadian Association of Genitourinary Medical Oncologists (CAGMO). Can. Urol. Assoc. J. 7(11-12), e797-e811 (2013). 
27. Khoo V. Modern management of penile cancer. EJC Suppl. 11(2), 303-306 (2013).

28. Seitz AK, Protzel C, Retz M, Arbeitsgemeinschaft Urologische Onkologie (AUO) der Deutschen Krebsgesellschaft e.V. Current state of chemotherapy in treatment of advanced penile cancer. Aktuelle Urol. 45(4), 286-292 (2014).

29. Protzel C, Seitz AK, Hakenberg OW, Retz M. [Neoadjuvant, adjuvant and palliative chemotherapy of penile cancer]. Urologe A 52(11), 1556-1560, 1562-1563 (2013). 